\title{
3
}

\section{Tailored simulation games for successful business process development}

\author{
P.Haho \\ TAI Research Centre, Helsinki University of Technology \\ P.O. Box 9555, 02015 HUT, Finland, tel. + 358-9-451 5032, \\ fax +358-9-451 3665, e-mail: paivi.haho hut.fi
}

\begin{abstract}
Enterprises suffer from a lack of strategy-based business process development methods in which, the dynamic knowledge creation as well as the implementation of a new process is present, already at the beginning of the project. The Softmatch Method is developed for this priviation. This article describes the principles of the Softmatch Method, and some empirical experiences. The Softmatch Method is a participative, systematic method, which is using customized simulation games as an integral part to achieve successful enterprise transformation in business process development. The Method involves different organization levels, and it is composed of different interactive elements, like teamwork, project management methods and simulation games. The participation of employees right from the beginning to design and implementation accomplishes high commitment throughout the whole transformation.
\end{abstract}

\section{Keywords}

Simulation games, business process development, dynamic knowledge creation, tacit knowledge, explicit knowledge 


\section{SOFTMATCH METHOD}

Softmatch is a creative, participative and systematic method of discovering the change potential of business processes, of realizing the changes needed and of managing the changes. The method is aimed at the development of processes to support rapid changes in industrial and service companies, as well as in public organizations. It can be applied to radical and incremental change projects.

In the Softmatch Method the process development is based on business strategy and customer needs. The ideas and views of personnel are an integral part of the development work. During the development projects, new modes of operation are actively sought, and their functionality is tested in simulations. The concurrence of planning and implementation leads to rapid change.

Softmatch stimulates the whole organization's creativity, and manages the ideas systematically and efficiently towards a competitive business process innovation. The method combines simulation games, teamwork and project management in an iterative system of learning and knowledge creation (c.f. also Nonaka and Takeuchi, 1995). Through acting and experimenting in the crossfunctional and cross-hierarchical simulation games, the method brings into the innovation process the tacit knowledge of the organization. Through teamwork and systematic project management, this tacit knowledge is converted into an explicit new process design. With the iteration rounds between simulations and project work, the innovation processs proceeds in a prototyping manner, until a sufficient design is created (Figure 1). The method adjusts the range of change to the prevailing change capability of the company. Ideally, small change steps result in radical business process change, if the direction of change is set at the beginning of the project, and the continuity of change is accepted and managed as a learning process (Smeds, 1996).

The Softmatch Method uses both "soft" change management features and "hard" project management principles to engage the knowledge, skills and creativity of the organization for process development:

a) "Soft" change management focuses on leadership, motivation, large-scale participation, communication, relationships within the organization, and ensuring the implementation of project results.

b) "Hard" project management helps to define clear strategy-based change objectives, to schedule the change project, and to manage its resources.

The Softmatch Method creates a clear and logical development framework, that respects and makes use of the skills and creativity of all organization members. Analysis and synthesis iterate in a rapid cycle for development. It combines a joint, realistic understanding of the present situation, hard business objectives, and a creative approach to change. Simulation games, teamwork, project work and intensive communication are used as part of the method, which proceeds in 
balance with the change capability of the personnel. Open communication is vital in change projects and without it, meaningful change cannot occur.

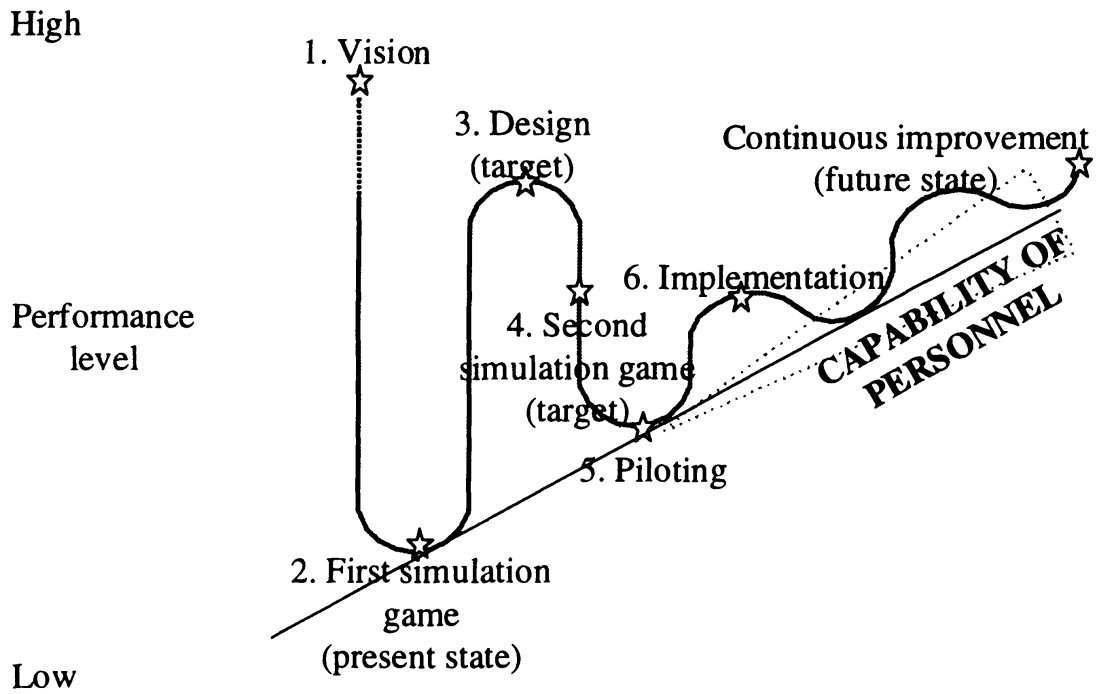

Time

Figure 1. The Softmatch Method proceeds in a prototyping manner towards an accepted process design.

The Softmatch is built on the basic principle of participation. It starts the discussion about process-oriented development between management, employees and experts. The method also enhances personnel's own initiative in process development, which is a crucial asset in the turbulence of the present competitive environment. This choice has been made to ensure the implementation of the new process as rapidly and smoothly as possible. The simulation phases in the method create a shared understanding of the process, which increases the motivation of the employees and the change flexibility of the organization. Commitment to change arises from understanding the whole. Committed people build up a wellfunctioning process, which is then reflected in the subsequent corporate image in the customers' mind.

The six Softmatch phases (Figure 2) add up to a dynamic method, where "hard" project management and "soft" change management elements alternate and overlap. Analysis and synthesis are combined for rapid development: the first simulation game constitutes the analysis of the present state, while synthesis is created in the design phase and in the second game. In the discussions, 
observations and solutions during the first game, synthesis for the new process are already being created.

Simulation gaming is systematic and visualized discussion about the activities and tasks in a chosen process, e.g. in the order-to-delivery process. To aid the simulation, the whole process is depicted on a big wall chart, and the meeting room is furnished as a "scale model" of the process.

The method allows the integration of human resources both vertically and horizontally during the change project, to achieve the best possible end result. Top management's role is vital in the first phase, when the target process and its development objectives are chosen, based on the strategy of the company. The piloting and implementation phases require top management support, commitment and participation as well. Throughout all the phases, the know-how of employees from different functions and hierarchical layers is crucial for successful change: the whole organization's resources have to be mobilized for change accomplishment.

At the beginning of the change project, individual change capabilities differ greatly: the common rhythm for change is missing. The change objective, the vision, can seem out of reach and detached from reality. The first simulation game harmonizes the change capabilities of the personnel and allows the change objectives in the latter phases of the project to become more demanding. Usually, the performance objectives are reached only after the implementation phase through continuous improvement.

In business process development projects, the first four phases of the method are realized in two to four months. The duration of the last two phases depends on the magnitude of the change and the size of the company. Smaller organizations can reap the benefits from change quickly, since all of personnel can participate in the design and experimentation of the new process in the simulation games. The implementation of the new process begins during the second simulation game and the need for change becomes obvious to everyone. In large global organizations, the implementation phase might take months, as it takes time to involve all the necessary personnel. 
Starting the Softmatch project

\begin{tabular}{|l|l|}
\hline 14 & $\begin{array}{c}\text { Choose the target process based on strategy, set } \\
\text { the objectives, organize the change project, inform } \\
\text { Duration:-12 dav }\end{array}$ \\
\hline
\end{tabular}

Top management of the company/ unit, change project team

First simulation game (present process)

\begin{tabular}{|c|c|}
\hline Prepare the simulation \\
Duration: 1 day
\end{tabular}

Change project team and employees knowing the different process phases 4-6 persons

Simulation game team 15-50) persons

Change project team 2-3 persons

Simulation game team: sufficient representation from all process activities, plus observers 15-50 persons

Development of the new process

\begin{tabular}{|c|c|}
\hline a & $\begin{array}{c}\text { Prepare the development phase } \\
\text { Duration: } 1 / 2 \text { - Iday }\end{array}$ \\
\hline $\mathbf{b}$ & $\begin{array}{l}\text { Design and model the new process, } \\
\text { establish subprojects } \\
\text { Duration: } 1-2 \text { daus }{ }^{*} \text { ) }\end{array}$ \\
\hline & $\begin{array}{l}\text { Run the subprojects to build up the } \\
\text { preconditions for the new process } \\
\text { Leadtime: } 12.2 \text { months }\end{array}$ \\
\hline & $\begin{array}{l}\text { Screen the results of the subprojects } \\
\text { Duration: } 1 / 2-1 \text { days }\end{array}$ \\
\hline
\end{tabular}

\section{Change project team 4-6 persons}

Process development team, typically $1 / 3$ of the simulation game team

$$
\begin{aligned}
& \text { Subproject teams, } \\
& \text { 2-5 persons per team }
\end{aligned}
$$

Process development team, typically $1 / 3$ of the simulation game team

$$
\begin{aligned}
& \text { Change project team } \\
& \text { 4-6 persons } \\
& \text { Simulation game team } \\
& \text { 15-5() persons } \\
& \text { Change project team } \\
& 2-3 \text { persons }
\end{aligned}
$$

Simulation game team: sufficient representation from all process activities, plus observers 15-50) persons

\section{Piloting the new process}

\begin{tabular}{|l|l|}
\hline 5 & $\begin{array}{c}\text { Pilot the new process, } \\
\text { ensure its preconditions }\end{array}$ \\
\hline
\end{tabular}
The responsible organization and
the implementation team

The responsible organization and the implementation team

Figure 2. The phases and steps in the Softmatch Method. 


\section{EXPERIENCES IN FINNISH PILOT COMPANIES}

\subsection{Case 1: Developing an order-to-delivery process in a manufacturing company}

\section{Background}

The company participating in the project is a Finnish company that develops, manufactures and markets products mainly for export. The annual turnover is approximately US $\$ 250$ million. The company operates internationally with around 1000 employees; its products are handled through both its own sales subsidiaries and through external channels. The entire business is divided into four strategic areas by business and product segment.

All efforts within the company to date had been concentrated on production. After years of slow development, business process reengineering became inevitable to improve competitiveness and cost efficiency. An overhaul of the operational management system was required and thus a careful study of the processes involved was necessary before defining the way forward.

The following objectives were set for change:

- create new process rules

- suppress work that does not provide added value

- reduce the number of activities in the process

- decrease process lead time

- improve delivery

- increase profitability

The condition of success was the wide participation by team members in the change being put into place; involvement would increase commitment and guarantee the implementation of the required changes. Other objectives included the promotion of autonomous initiatives for continuous development, as well as continuous change and learning with high flexibility. Simulation games were therefore chosen as a change management tool.

\section{Essential points of the change project}

The first simulation game. The participants in the first simulation game were staff carrying out the daily order-to-delivery process, co-workers in the support processes, the IT manager, as well as directors and managers in related operations within the company. A total of 50 employees attended the game; 18 actively played and the rest observed the simulation.

The simulation game was a systematic and visualized discussion about the activities and tasks in the order-to-delivery process. To aid the simulation, the whole process was depicted on a big wall chart and the meeting room was 
organized to represent a "scale model" of the process. Computers and genuine order documents were used as simulation material.

The simulation was carried out by "reproducing" the handling of a customer order through the whole process, from initiation of the order to delivery. An inhouse change champion prepared the simulation game and informed the organization about the change project and the simulation, while an external facilitator led the simulation and discussions.

One hundred and twenty-seven ideas, open questions and problems were identified during the simulation session. These were written on stickers and attached to the process description on the wall. The ideas were classified as follows:

- reorganization and shortening of the process

- clarification of the product range

- clarification of the process rules

- specification of the rolling forecast and capacity planning process

- modernization and intensification of the use of IT

- increase in the cooperation between production and sales

During the game decisions could be made. Seven different problems were addressed and resolved. Many decisions were made concerning the process control. Because decisions were being taken during the game, involving all the relevant parties, the interest level stayed high throughout and the actions decided upon during the simulation could be easily implemented afterwards.

The development of the new process and the second simulation game. Once the first simulation game had taken place, the next step was to develop the new process. The new process description was created by the process development team. The team had 24 members from different activities within the process who had taken part in the simulation game. Each function and hierarchical level was represented to ensure the best possible result. The team designed and modeled the new process.

Four parallel sub-projects were established to solve the prerequisites for the new process. The sub-project teams consisted of 4-6 people and were divided by subject:

- customer classification

- concepts and terminology in the process

- rules of operation

- relation between strategy and processes.

During the second simulation game, the new process and the new mode of operation were tested and improved upon with the complete simulation group. 
Hypothetical customer orders were simulated; once again many ideas for improvement arose, were discussed, and subsequently became an important resource for the later phases of the change project.

\section{Results}

Results achieved during the simulation period. The two simulation games took place between August and October 1995. During this time the following results were achieved:

- a joint understanding of the past situation was reached

- the order-to-delivery process was defined and documented

- the business processes were planned and simplified prior to information system investments

- the role of the production process relative to the order-to-delivery process was clarified

- a common and unified terminology was developed that allowed clear, shared concepts

- an understanding of the importance of team work was achieved.

The business process design that was reached shortened the process from 30 to not more than ten steps per production line. The number of people involved in the process chain could be decreased from eight to three by combining tasks and reducing unnecessary steps by effective teamwork.
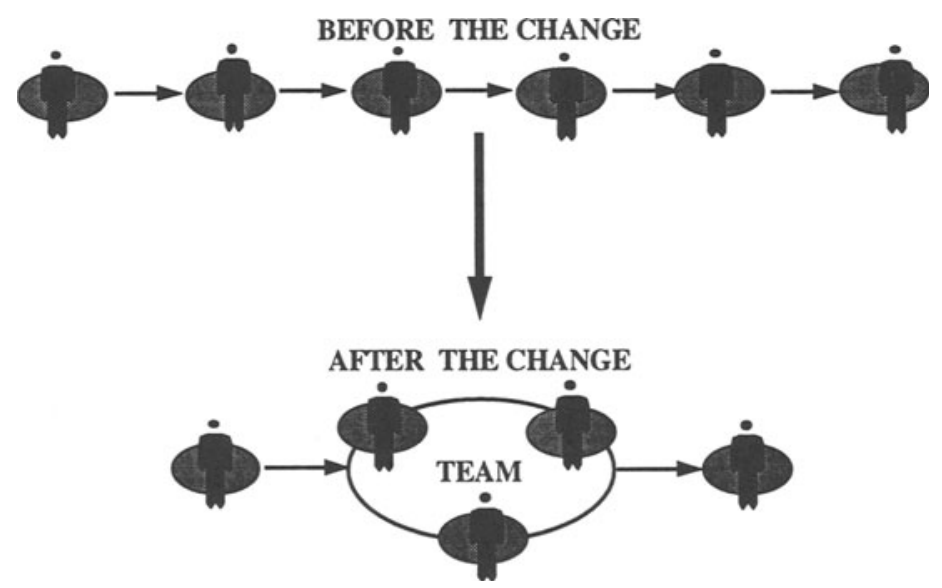

Figure 3. The possibility to use teamwork in the process was discovered during the simulation. 
The participants reported that:

- The simulation games created a holistic understanding of the lead times and problems in the order-to-delivery process; for the first time the complex process was understood as a whole.

- All the people involved were, at last, present at the same time and were listened to. The managers with decision-making power were also present.

- It was important for everyone to see and understand the interconnections between activities and tasks. The simulation team can visualize the whole process whereas one person alone would be blind to many alternative solutions.

- Many new ideas were conceived.

- The simulation was a good training tool for smaller groups and newcomers.

Results achieved after the simulations. Six months after the second game, the simulations were a shared experience that were still referred to in the development process. The decisions made during the simulations were still valid. The simulation had provided a good basis and direction for future business process development and had helped to clarify the change objectives.

After the simulation games, two groups were established to foster teamwork within the company. Office workers, i.e. the people in the order handling, invoicing and dispatching departments, visited and worked in each other's jobs to learn the principles of teamwork. Information and training sessions were arranged and the payment system came under discussion.

The objectives of the change project were met within six months:

- The new process rules were for the most part implemented. The clarified process rules impacted directly on decreasing process lead time, eliminating work that was not providing added value, and improving delivery performance.

- Preparatory work for the new processes had already started with team training and related projects.

- The new process design and the clarified process rules had a powerful impact on the development of the new IT system, which proceeded effectively based on the process descriptions developed in the simulation games.

Finally, process reengineering and information system projects take time to put into place. Moreover, profitability can only be assessed after the implementation of radical change. At the date of publication, the final results of these two objectives had not been published. 


\subsection{Case 2: Developing an order-to-delivery process in small improvement steps}

\section{Background of the company and of the change project}

The corporation involved in this project develops, manufactures and markets high quality hospital technology systems and services for export internationally. Its turnover is about FIM700 million and the company employs about 600 people. The corporation consists of four companies, which have a joint sales and distribution network.

The aim of the development project was to analyze the present state of the sales-to-delivery process and then improve it little by little.

The objectives of the Softmatch project and of the simulation games were to:

- gain an overall picture of the process to be developed

- improve the efficiency of the present process through improvements in

- throughput time

- delivery accuracy

- quality of operations

- turnover of capital

- support the design and experimentation of the new process

- increase the flexibility of the process and its ability to learn and change

- ensure the implementation of change through empowerment

\section{Essential points of the change project}

First simulation game. A total of 30 people participated in the first game, 17 as players and the rest as observers. The game followed case histories, supported by the process description on the wall. Two different case histories were used: a typical customer order, and an unusual order fraught with technical problems, material shortages and missing documents. During the game, ideas were developed on how the efficiency of the process could be improved, how unnecessary work and phases in the process could be dropped, and how problems could be solved.

The game produced 119 ideas, open questions and problems, out of which 100 concerned the sales-to-delivery process itself, while the remainder addressed support processes.

Based on the perceived ideas, open questions and problems, the development targets were grouped as follows:

- the process and its phases

- the information flow 
- material flow and control, buffers, capacity, flexibility and accuracy of delivery

- information systems

- product changes and their management; disturbances

- training

Development of the new process and the second simulation game. The development and modeling of the new process was performed three weeks after the first simulation game. The two-day workshop was attended by about 15 people from the sales-to-delivery process and its support processes. In the workshop, the results of the first game were analyzed and the development objectives of the process were refined. These objectives were the starting point for designing the new process. After the new process description was finalized, the need for subprojects was discussed. Resources were allocated to the sub-projects in order to create the preconditions for the new process, and time schedules were planned.

The themes of the sub-projects were:

- inventory and control of materials - fixing the buffer stocks required

- classification of orders and delivery times

- process measures

- managing delivery prohibitions

- elimination of unnecessary documents

- planning the second simulation game, taking into account the results from the sub-projects

The second simulation game was played according to the new process description, applying the new "rules of the game". The aims of the second game were to test the new process, its prerequisites and its rules, to train employees in the new mode of operation, and to stimulate development.
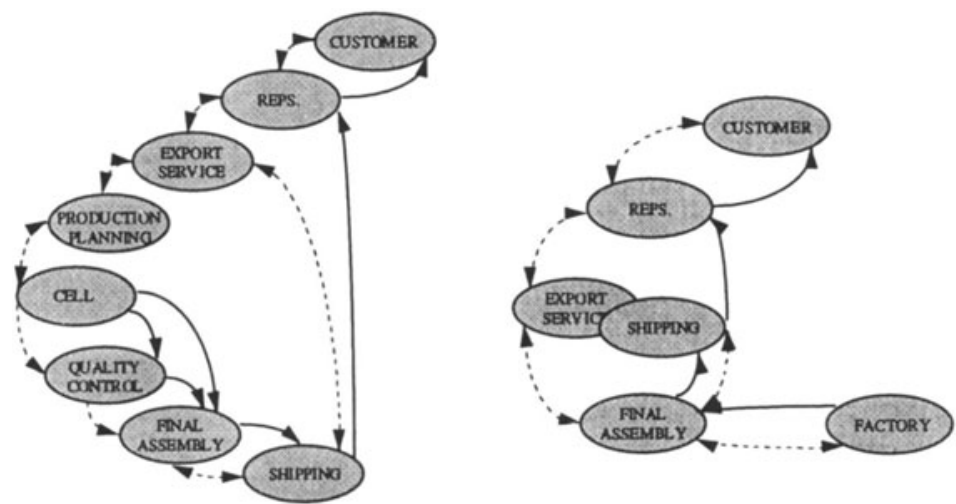

Figure 4. Process structure before and after the Softmatch project. 
An important feature in the development project was that production was customer-driven only until final assembly; the job shop and the suppliers ran support processes that deliver the components to final assembly. The intermediary buffer inventory between final assembly and the job shop plays an essential role in the smooth functioning of the sales-to-delivery process. When this buffer works well, unnecessary inquiries can be avoided, delivery accuracy remains good and flexibility is ensured.

While the new structure of the process did not change much, the prerequisites for its functioning changed considerably.

Piloting the new process. The pilot phase was planned with a restricted amount of sales areas and products in order for it to be manageable. If the pilot was successful, the new mode of operation would then be spread to the wider process.

\section{Results}

The project resulted in many small improvements. People implemented improvements both during the pilot phase and after. The many inefficiencies of the process were eliminated and unnecessary activities completely dropped.

The rules of cooperation between sales and production were clarified and recognized. The same issues were understood differently in different parts of the process. The clarification of concepts facilitated inter-functional cooperation and thus increased flexibility. Sales and production now communicate and genuinely cooperate.

As a result of the project, customers could be given more accurate delivery dates and the rules for handling orders for project deliveries and quick deliveries could be explicited. The principles underlying production control were re-assessed and the levels of buffer inventories were adjusted to correspond to demand.

Production flexibility improved and delivery accuracy has remained high.

\section{CONCLUSIONS}

Experience with nine pilot companies as external process development facilitator has demonstrated that it is essential to combine the development work into a systematic framework, which we call Softmatch. The Softmatch phases add up to a dynamic method, where "hard" project management and "soft" change management elements alternate and overlap, and where different development methods and tools are combined and used during a change project. 
In the Softmatch framework (see Figure 2) special emphasis is put:

1. on the preparatory strategic analysis of the change need and the goals of the project. The change has to be organized into a formal change project of the company.

2. on carefully informing the whole organization about the change and the simulation games.

3. on the right composition of the different teams involved during the whole change project (see Figure 2 right hand column)

4. on the importance of the development phase between the simulation games, and the role of the sub-project teams to build the preconditions for the new process.

5. on flexibility in using the framework: the day-to-day operations, other ongoing change projects and learning during the change project itself require iterations and adjustments to the method. In fact, the change objectives are often modified during the project.

6. on the fact that the successful change project requires that first an internal change champion and then the whole organization take over the method and drive the change towards implementation.

The Softmatch Method helps the organization to test the new mode of operation and its functionality before implementation and it encourages employee initiative and rapid process-oriented decision making. The method also increases the employees' shared understanding and customer focus as well as improves relationships and collaboration between people and functions.

In the Softmatch Method, the present state of the process is modeled rapidly and cost-efficiently. Heavy analyses are avoided; rather, energy is saved for the discovery of new solutions and establishing the change. The systematic, simultaneous and visual connection between all individuals concerned results in joint understanding of the present situation and its change needs, acceptance of the need for change and the means to achieve it and rapid and smooth implementation of the new mode of operation.

\section{REFERENCES}

Haho, P. (1992) 'Game experiences from Neles-Jamesbury' in: Ruohomäki, V., Vartiainen, M. (eds) Simulation games as educational tools in the learning organization (in Finnish). Helsinki University of Technology, Industrial Management and Industrial Psychology, Report 140, TKK OFFSET, Espoo, 1992, 45-49.

Haho, P. and Smeds, R. (1996) Softmatch: Enterprise Transformation through Simulation Games, Experiences, in Manufacturing Agility and Hybrid 
Automation-I (eds. R.J. Koubek and W. Karwowski), IEA Press, Louisville, 1996, 571-574.

Haho, P. and Smeds, R. (1996) Benefits from using simulation games in business process development. Experience from a Finnish manufacturing company. In: N. Okino, H.Tamura and S. Fujii (Eds.) Advances in Production Management Systems. Proceedings of the $6^{\text {th }}$ IFIP TC5/WG5.7 International Conference APMS '96, Kyoto, Japan 4-6 November, 1996, 267-272.

Haho, P. and Smeds, R. (1997) The Softmatch Method: Enterprise Transformation through Simulation Games, in The Simulation and Gaming Yearbook, Volume 5, Games and Simulations for Business (ed. D. Saundes and M. Vartiainen), Kogan Page, London .

Haho, P., Smeds, R., Blatti, S., Birbaum, D., Laine, K. and Gustafsson, B. (1997) The Softmatch Method. Management of Business Process Development Projects using Simulation Games. Process Developer's manual. S.A.M.I. Oy, Helsinki (77 p.)

Kimberley, J.R. 'Reframing the Problem of Organizational Change', in Paradox and Transformation, R.E. Quinn and K.S. Cameron (eds.), Ballinger Publishing Company, Cambridge, Mass., 1988, 163-168.

Laakso, T., Hakamäki, J., Forsberg, K. and Smeds, R. (1995): 'Process assessment and simulation games methods and software supported tools in Business Process Re-engineering', in: Proceedings of the IFIP WG5.7 Workshop in Galway, Ireland, April 20-21, 1995. Chapman \& Hall, London (10 pages, forthcoming).

Mintzberg, H. (1994a) The Fall and Rise of Strategic Planning, Harvard Business Review, 1994, January-February, 107-114.

Nonaka, I. and Takeuchi H. The Knowledge Creating Company, Oxford University Press, Oxford, 1995.

Ruohomäki, V. (1994) Participative Development and Organizational Learning with Work Flow Game, in Change, Learning and Mental Work in Organizations - Working papers of the 3rd Otaniemi-Dresden workshop (eds M. Vartiainen and V. Teikari). Helsinki University of Technology, Industrial Economics and Psychology, Report 157, Espoo, 63-75.

Ruohomäki, V. (1995a) Viewpoints on learning and education with simulation games, in Simulation Games and Learning in Production Management (ed. J. Riis), Chapman \& Hall, London, 13-25.

Ruohomäki, V. (1995b) A simulation game for the development of administrative work processes, in The Simulation and Gaming Yearbook, Volume 3, Games and Simulations for Business (ed. D. Saunders), Kogan Page, London, 264270.

Smeds, R. (1997) Organizational learning and innovation through tailored simulation games: Two process reengineering case studies. Knowledge and Process Management. The Journal of Corporate Transformation, Vol 4, No 1, 22-33. 
Smeds, R. (1996) Successful transformation: Strategic evolution management for competitive advantage, Business Change and Re-engineering. The Journal of Corporate Transformation, 1995, Vol 3 Number 2, $62-72$.

Smeds, R. and Haho, P. (1995a) Tailored order-to-delivery process game, in Simulation Games and Learning in Production Management (ed. J. Riis), Chapman \&Hall, London, 145-155.

Smeds, R. and Haho, P. (1995b) Simulation games in business process reengineering, in The Simulation and Gaming Yearbook, Volume 3, Games and Simulations for Business (ed. D. Saundes), Kogan Page, London, 246-253.

\section{BIOGRAPHY}

Päivi Haho, MSc (Eng) is a researcher at Helsinki University of Techology, TAI Research Centre. Earlier she has been responsible for the management of change projects in international business process reengineering projects in industry. She has developed simulation games (since 1988) and business process development methods in her jobs. Her current research interests include participative management of change in enterprise transformation and dynamics of knowledge creation and accumulation in industrial organizations. 